\title{
Requirements for Aerial Mapping Using UAV-photogrammetry Technology: Baltic Sea Coast Measurement
}

\author{
Lina Kukliene ${ }^{1}$, Dainora Jankauskiene ${ }^{1,2}$, Indrius Kuklys ${ }^{1}$, Birute Ruzgiene ${ }^{1},{ }^{1}$ Klaipeda State \\ University of Applied Sciences; ${ }^{2}$ Kaunas University of Technology
}

\begin{abstract}
The use of Unmanned Aerial Vehicles (UAVs) with the integrated camera for image capturing, GPNS, the management equipment and specialized software for processing of images has been rapidly expanding for aerial mapping. The quality of cartographic products at the initial stage depends on well-designed technical specifications for photogrammetric mapping and conditions of the project realization. The successful photographic mission and efficiency of the performed photogrammetric processes should be specified by the requirements that meet not only the needs of Lithuania but also those of the European Union. Thus the paper deals with the analysis of the essential requirements for aerial mapping due to the application of the highly advanced UAV-Photogrammetry technology, as well as outlines conditions and parameters that can be used for preparing and specifying the documentation of aerial photogrammetric workflow and realization of a project. The methodology for the determination of mapping costs is developed and the example of efficiency evaluation is presented which is based on the photogrammetric data gained by UAV technology using an experimental object which is mapping of the Baltic Sea coast at Palanga city in Lithuania.
\end{abstract}

Keywords: Unmanned Aerial Vehicles, aerial mapping, photogrammetric requirements, costs evaluation.

\section{Introduction}

The aerial mapping is one of the most advanced methods to obtain information about the surface of the Earth and other objects using photographic images. The quality of images and cartographic products mainly depends on the success of aerial photography mission, qualified guidance of photogrammetric works, and appropriate realization of aerial mapping requirements that meet the needs of Lithuania and preferences of the European Union.

Recently, the interest of application of small planes flying at low altitude, the so-called Unmanned Aerial Vehicles (UAV) in photogrammetric and geodetic environment is rapidly growing in many countries including Lithuania. Unmanned Aerial Vehicle with the integrated digital camera and automatic management of taking photography is an effective platform equipped with UAVPhotogrammetry technology that is used for digital photogrammetric data processing and generation of the aerial mapping products. The UAV platform is also named a Remote Operation Aerial Vehicle (ROAV). The UAV-Photogrammetry technology is increasingly replacing the classical methods applied in geodetic, cadastral, etc. measurements. The main advantages of UAV application are the following: the costs for getting aerial mapping product is not high (decreasing), images are collected fast and in real time, there is also a possibility of taking a photography of the territories where the relief is complicated or it is not possible to reach the object, moreover, the processing of images is fast, and the created cartographic products fulfill the requirements of accuracy.
UAV-Photogrammetry is applied in many fields, for example, for taking images when the leaves of the trees are covering the objects of surface; on the other hand, close-range photogrammetry is used for mapping of the linear objects (network of roads, sea coasts, etc.), and for fixing the position of electricity networks, as well as for measuring the cultural monuments for reconstruction, and, ultimately, for creating the cadastral maps, etc. ([3], [14], [8], [2]).

The orthophoto maps of high accuracy (quality) and three-dimensional surface models are main products generated by the use of aerial photogrammetric technology. The aerial mapping products are presented to consumers in the form of digital maps, and digital terrain or 3D surface models can be processed by the use of GIS applications ([7], [9]).

The goal of the research is to analyze the features and parameters for aerial photography by the use of Unmanned Aerial Vehicle and to outline the main photogrammetric requirements that can be accepted as the basis for preparing the technical specification of aerial mapping project and realization of photogrammetric workflow applying the UAVPhotogrammetry technology.

1. Project specification for aerial mapping applying UAV-Photogrammetry technology

The initial stage of the territory mapping project/ technical specification preparation indicates the main objective of the project works and identifies its parts, i.e. project tasks and objects. The detailed data of aerial mapping object should be specified, such as: 
width, length, area, dislocation of territory (a scheme is provided in the cartographic material), and features of the relief, etc. For aerial photography on the border area it is mandatory to apply to the relevant authorities in order to obtain all necessary permits. The deadlines for all aerial mapping works have to be foreseen.

\section{Common conditions for aerial photography.}

Aerial photography can be executed in good meteorological conditions, i.e. in light wind (when speed is of $1.6-3.3 \mathrm{~m} / \mathrm{s}$ ) and in minimal cloudiness. The calendar time of aerial photography is determined taking into account the specific meteorological conditions of the seasons. The aerial photography is usually performed early in spring until the vegetation has not yet cropped, or, on the other hand, late in autumn, so that the leaves of the trees have not covered the ground surface. Aerial photography of the object on the seaside can be realized in spring before the stormy season begins (preliminary in March) and/ or in the autumn, after the stormy season has ended (e.g. in November). The time for aerial photography depends on the general conditions of the Earth's surface and the sun's height. It's best to take photographs at noon, when the falling shadows are the shortest. The geometric, visual and informative features of photographic images depend on the technical means of the aerial photography, such as: type of platform and the integrated sensor for photographic imaging, i.e. the properties of the digital camera, and, additionally, on geodetic measurements creating a photogrammetric base network.

\subsection{Technical means: UAV, digital cameras}

Taking photography of an area is carried out by a camera integrated at Unmanned Aerial Vehicle with the automatic management and control system or at planes that meet the requirements for aerial mission over the territory. Photographic and photogrammetric data are collected in half automatic or automatic manner.

The Unmanned Aerial Vehicles of different type, classification and category can be used as a platform for area photography from low altitude, see Figure 1 $([1],[18],[15])$.

b)

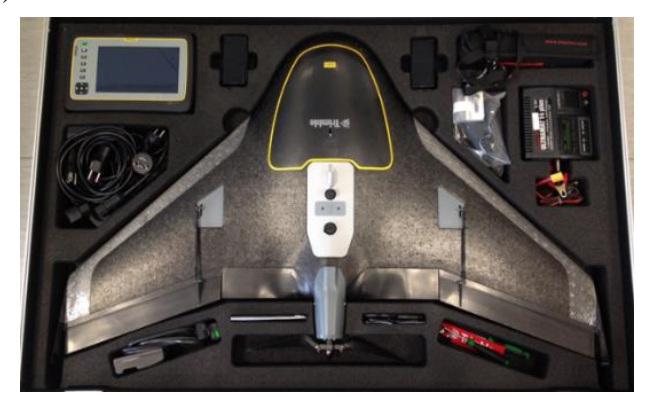

Fig. 1. UAVs used at different projects in Lithuania: a) four-wheel helicopter with mounted camera; b) a set of fixed-wing UAV, model UX5 Trimble

For area photography, the unmanned vehicle flies at low speed (about 50-60 km/h) and the flight height ranges from $30 \mathrm{~m}$ to $750 \mathrm{~m}$. The Vehicle can fly at even $12 \mathrm{~m} / \mathrm{s}$ wind speed, and it can land under complicated conditions ([17], [10]).

For example, the platform of fixed-wing UAV, UX5 Trimble is of low cost and weight platform with foam construction. A wingspan is of $1.0 \mathrm{~m}$ and the weight is $2.5 \mathrm{~kg}$. Dimensions of UAV are $100 \times 65 \times 10$ $\mathrm{cm}$. The UAV cruise speed is $80 \mathrm{~km} / \mathrm{h}$ and can fly up to $50 \mathrm{~min}$ on low wind and in light rain. A flight range is approx. $60 \mathrm{~km}$, some extra for launching and landing. The maximal communication and control range is up to $5 \mathrm{~km}$. The guidance of UAV platform can be full automatic, semi-manual or manual. The take-off of the platform, flight and landing on the surface can be executed in an automatic or manual mode. The flight planning software allows optimal guidance of the flight.

The main features of digital cameras are as follows: focal length, geometric and radiometric resolution of the sensor, pixel size; features of the optical system, and formats (saving) of photographs. The sensor's pixel size is an important parameter that defines sensor sensitivity and optical resolution. Radiometric resolution indicates spectral properties, i.e. the saturation (intensity) of the images color is expressed in bits for pixel. The small pixel size determines the light sensitivity and in a diversity of weather conditions affects the quality of the photographs. The camera's optical system must be fixed, i.e. the focal length is constant. A fixed optical system increases the stability of the camera's internal geometry ([6]).

A higher shutter speed should be used to eliminate motion blur. Even at slower flying speeds, a wind gust resulting in a roll or a small change in pitch and longer exposure times can lead to motion blur. Image blur causes the radius of uncertainty in tie point matching to increase by a factor of 4 , which has a direct effect on the resulting vertical accuracy in the point cloud and DSM.

The example of camera's features is presented in Table 1. A high-resolution professional camera Sony 
$N E X-5 R$ with fixed-optics Voigtlander lens was used for taking images over the test area, namely the Baltic Sea coast extending along Palanga city.

Main features of high-resolution professional camera Sony $N E X-5 R$ with fixed-optics

\begin{tabular}{|l|l|}
\hline \multicolumn{1}{|c|}{ Features } & \multicolumn{1}{c|}{ Sizes } \\
\hline Focal length & $15 \mathrm{~mm}$ \\
\hline APS-C sensor & $16.1 \mathrm{Mega}$ pixels \\
\hline Full frame size of image & $4912 \times 3264$ pixels \\
\hline Sensor's area & $365.04 \mathrm{~mm}^{2}$ \\
\hline Size of sensor & $23.40 \times 15.60 \mathrm{~mm}$ \\
\hline Pixel size & $4.8 \times 4.8 \mu \mathrm{m}$. \\
\hline $\begin{array}{l}\text { Fixed-optics Voigtlander lens increase the stability of the camera's internal geometry. Small pixel size } \\
\text { determines the light sensitivity and sharp images can be acquired. }\end{array}$ \\
\hline
\end{tabular}

Aerial photography should be executed with a digital camera having a sensor's size not less than 12 MP and radiometric resolution -24 bits.

\subsection{Aerial mapping project realization}

The photogrammetric network is created for the external orientation of photographic images and for generation of photogrammetric products. For this purpose, geodetic points (targets) are projected and before taking images targets at the area are marked by artificial, background contrasting special marks. After aerial photography, these marks must be clearly visible in photographic imagery. The dimensions of the mark may be $40 \times 40 \mathrm{~cm}$. In order to obtain more precise aerial mapping products, the targets are distributed in a specific order: at the beginning, at the end and at the middle of the flight patch as well as in the areas of complicated relief. The coordinates of the targets are determined by geodetic methods, measured by electronic geodetic instruments, and often by the Global Positioning System (GPNS) using GPS network data. The coordinates of the targets are determined by the GPS method with an accuracy of $5-10 \mathrm{~cm}$ ([11]).

The GPS module integrated at UAV allows to determine the geodetic coordinates of each image projection center during the flight, thus reducing the need of geodetic reference points. Taking images over a territory when the vehicle is equipped with GPS and gyroscopic stabilization equipment, the accuracy of the aerial images is about $\pm 10-15 \mathrm{~cm}$. After aerial photography, a catalog of GPS coordinates and projection centers of aerial photographs as well as layout diagrams are provided.

\section{The parameters for aerial photography mission.}

Before the aerial photography, the UAV flight height above the surface (Aerial Ground Level (AGL)) during image acquisition is determined and the camera's technical characteristics are evaluated. The flight height depends on the required resolution of the photographic images (the size of the image pixel in the area - GSD (Ground Sample Distance), the camera sensor's pixel size and focal length ([13], [5]).

The resolution of photographic images describes the accuracy of photogrammetric products and can range from $2.4 \mathrm{~cm}$ to $24 \mathrm{~cm}$. The GSD is calculated according to the formula:

$$
G S D=p \frac{A G L}{c},
$$

where $p$ is the pixel size of the sensor, $\mu \mathrm{m} ; A G L-$ aerial ground level, $\mathrm{m} ; c$ - camera focal length, $\mathrm{mm}$. For example, if the required resolution of the images is $2.4 \mathrm{~cm}$ and the Sony NEX-5R camera (see camera's features) is used for taking photographs, the flight height above the surface will be $75 \mathrm{~m}$.

Prior to a flight the camera is turned on, the ISO is determined to auto mode, F-value 4.5, the focus of camera is fixed and shutter speed is regulated depending on the weather conditions, terrain features and desired images overlap.

The flight planner software (e.g. Aerial Imaging, Trimble) provides optimal flight performance. After checking the parameters of the UAV, the flight mode is shifted to the automated flying. When UAV achieves the appointed height, the process of taking pictures starts. The software operates not only the UAV, but also is managing camera exposure ranges. Therefore, the image acquisition becomes completely automatic.

The overlapping of photographs is an important parameter for obtaining high quality cartographic products. The best results are obtained when an overlapping is more than 5 photographic images. Taking into account that the UAV system is unstable during the aerial photography the position mostly depends on the wind gusts, so it is recommended that $70-80 \%$ of images have to be overlapping.

After the realization of the aerial photography, the basic features of the gained images are presented as follows: original size (pxl.), resolution (dpi), pixel size $(\mu \mathrm{m})$, frame format $(\mathrm{cm})$, images size in the area $(\mathrm{m})$, radiometric resolution (bit), and memory 
capacity $(\mathrm{Mb})$. Photogrammetric and photographic image quality is evaluated.

The processing of photographic images, accuracy and acquired products.

The application of the digital photogrammetric software (e.g. TBC Photogrammetry Module, Aerial Imaging, Trimble) allows to transform images into the required coordinate system (the process of exterior orientation), and thus are the orthophoto maps generated and created the three-dimensional model (3D). For more convenient data analysis and visualization, an orthophoto map can be divided into blocks. The generation step (resolution) for the orthophoto is defined. Since the UAV runs at low altitudes, it is recommended to generate an orthophoto map at the step of $10 \mathrm{~cm}$.

The following generalized rule applies for the accuracy evaluation of aerial mapping products, which means that the precision of planimetric coordinates must be twice as high as the GSD, whereas the altitudes must be higher three times. In addition, the Trimble Corporation declares the following criteria for assessing the accuracy of UAVPhotogrammetry data, the mean and maximum errors of planimetric coordinates are $1.0 \times \mathrm{GSD}$ and 1.6 $\times \mathrm{GSD}$, and elevations of $1.6 \times \mathrm{GSD}$ and $2.5 \times \mathrm{GSD}$. For example, if GSD $=2.4 \mathrm{~cm}$, then the mean and maximum errors in the $\mathrm{x}$ and $\mathrm{y}$ directions are $2.4 \mathrm{~cm}$ and $3.8 \mathrm{~cm}$; direction $\mathrm{z}-3.8 \mathrm{~cm}$ and $6.0 \mathrm{~cm}$.

An orthophoto map, the geometric and radiometric features of which meet the requirements, is presented to the user in the appropriate format (e.g. GEO TIF). Cartographic products can be delivered to customers by means of interactive maps and threedimensional models of surface. At the next step, the obtained cartographic digital data is processed and archived by ArcGIS or by another type of software, and the required production is presented for the user in the GIS server or is located on another web site.

\section{Costs and effectiveness consideration}

Currently, when various technologies for the image acquisition, management and processing are available, it is important to consider the costeffectiveness of a certain aerial mapping with the UAV application. In general, the price of the product comprises an actual expense plus overheads. Overheads vary greatly regarding the salary structure of administrative services and the amount of taxes to be paid ([4], [16]).

The example of cost strategy is presented and based on the executed UAV flight mission over the Baltic Sea coast at Palanga city and generation of aerial mapping products stages. The territory is photographed with a Sony $N E X-5 R$ digital camera, equipped into the vehicle $U X 5$, Trimble. The length of the patch is about $2 \mathrm{~km}$ (approximate area - $43 \mathrm{ha}$ ), the size of the pixel in the area (GSD) is $3 \mathrm{~cm}$, and about 400 photographs are received. An orthophoto map was generated by Aerial Imaging software and a 3D coastal modeling was performed, see Figure 2.

The area covered by images during the flights is related with height of flight (AGL) and is one of important factors for the UAV mission duration and project cost evaluation ([12]). Table 2 presents the data of imaging area according to the different GSD and flying height (AGL).

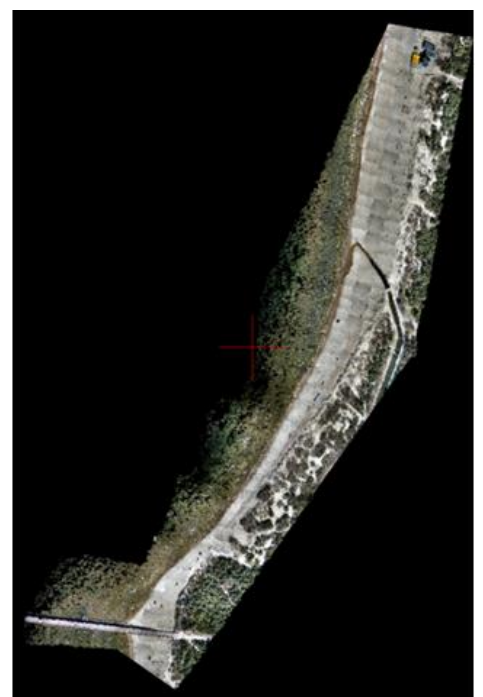

Fig. 2. Orthophoto map of the Baltic Sea coast at Palanga city generated by the use of UAV-Photogrammetry technology 
Imaging area depending on GSD and AGL (Sony NEX-5R, UX5 Trimble)

\begin{tabular}{|c|c|c|}
\hline GSD, $\mathrm{cm}$ & AGL, $\mathrm{m}$ & Image size on ground (imaging area), $\mathrm{m}$ \\
\hline 2.4 & 75.0 & $117.8 \times 78.3$ \\
\hline 3.0 & 93.7 & $147.3 \times 97.9$ \\
\hline 5.0 & 154.2 & $245.6 \times 163.2$ \\
\hline 10.0 & 312.5 & $491.2 \times 326.4$ \\
\hline 20.0 & 625.0 & $982.4 \times 652.8$ \\
\hline 24.0 & 750.0 & $1178.9 \times 783.4$ \\
\hline
\end{tabular}

Before the UAV flight the preparation works are as follows: reconnaissance of territory, planning of ground control points (GCP), marking of GCPs on the area, determination of signalized and natural (features) points' coordinates using geodetic techniques. The efficiency of the preparation works of UAV flight mission is presented in Table 3.

Time costs for preparation and UAV flight mission

TABLE 3

\begin{tabular}{|l|c|}
\hline \multicolumn{1}{|c|}{ Stages } & Efficiency, $\mathrm{h}$ \\
\hline Reconnaissance of territory & 1 \\
\hline Ground control points projecting (23 points) & 1 \\
\hline Signal preparation and marking (6 points) & 1.5 \\
\hline Coordinate determination of GCPs & 1 \\
\hline UAV flight mission realization (1 path), 2 executers & 1.5 \\
\hline \multicolumn{2}{|c|}{ Total } \\
\hline
\end{tabular}

The performance details of photogrammetric triangulation (AT), DEM and digital orthophoto modelling with 400 images (one path) for aerial generation (DOM) are listed in Table 4.

TABLE 4

Time duration for images processing

\begin{tabular}{|l|l|c|c|}
\hline Processes & \multicolumn{1}{|c|}{ Operation (400 images) } & \multicolumn{2}{|c|}{ Time duration, val. } \\
\cline { 3 - 4 } & & Automatic & Manual \\
\hline \multirow{4}{*}{ AT } & Data preparation & - & 0.5 \\
\cline { 2 - 4 } & Tie points matching & 3 & - \\
\cline { 2 - 4 } & GCP measurement & - & 1.5 \\
\cline { 2 - 4 } & Block adjustment & 1 & - \\
\hline \multirow{3}{*}{ DEM } & Image matching & 2 & - \\
\cline { 2 - 4 } & Data filtering & 0.5 & - \\
\cline { 2 - 4 } & Post processing & 0.5 & - \\
\cline { 2 - 4 } & Editing & - & - \\
\hline \multirow{3}{*}{ DOM } & Orthophoto generation & 1.5 & - \\
\cline { 2 - 4 } & Color adjustment & 1 & - \\
\cline { 2 - 4 } & Mosaicking & 2.5 & 3 \\
\cline { 2 - 4 } & Editing & - & 7 \\
\hline & & & 12 \\
\hline
\end{tabular}

The generation of mapping production (automated processes) is based on costs per image $(0.5 €)$ plus labor (manual) costs per hour $(5 €)$. Therefore, total cost for processing of 400 images is $235 €$, see in Table 4.
Concerning data mentioned above, the aerial photography costs consist of a base cost for preparation works (transportation and overheads as well) plus a charge for the image area and regarding of pixel size (GSD). Table 5 shows the price-list in consideration of mapping area. 
Price-list for aerial mapping

\begin{tabular}{|c|c|c|c|}
\hline \multirow{2}{*}{ Area, ha } & \multicolumn{3}{|c|}{ UAV aerial photography cost, EUR } \\
\cline { 2 - 4 } & GSD 3 cm & GSD 5 cm & GSD 10 cm \\
\hline Up to 2 & 570 & 340 & 280 \\
\hline $2-5$ & 740 & 400 & 280 \\
\hline $5-10$ & 970 & 450 & 400 \\
\hline $10-15$ & 1,430 & 510 & 570 \\
\hline $15-50$ & 2,000 & 860 & 680 \\
\hline $50-100$ & 3,400 & 1,400 & 800 \\
\hline
\end{tabular}

The costs for UAV-Photogrammetry experimental project (one path - area 43 ha, at GSD $-3 \mathrm{~cm}$ ) realization is EUR 2,000 (see Table 5) and plus cost for image processing, in total $-2.235 €$.

The costs variation for UAV-Photogrammetry (aerial mapping) application depends on the calculations of product providers, including special employment as well. Undoubtedly, mapping companies can provide different costs for aerialimaging by UAV systems and photogrammetric data processing. The estimation of the works (price and time) usually dependent on the skills, experience of employment, equipment available, the amount of salary for the employees, and the cost for administration of the project, etc.

\section{Conclusions}

The interest in Unmanned Aerial Vehicle's great potential for the aerial mapping is growing in many countries including Lithuania. Unmanned Aerial Vehicle in combination with photogrammetry provides low cost, a small area, and prompt data collection used for image processing and demonstrates the modern technology employed for environment imaging. The photogrammetric requirements for aerial mapping project realization are developed, when low-flying (up to $750 \mathrm{~m}$ ) Unmanned Aerial Vehicles is applied as a platform with integrated camera, flight control system, and GPS for flight mission.

The UAV-Photogrammetry project's workflow specifications outline the following main data, requirements and parameters:

- location of an object, size of the territory, features of the terrain and project completion dates; the required accuracy of the aerial mapping products that is specified by the customer (e.g. $10 \mathrm{~cm})$;

- the pixel size in the area (GSD), taking into account the accuracy of the aerial mapping products required;

- depending on the size of a camera's sensor and the GSD, the flying height (AGL) of the Unmanaged Aerial Vehicle should be defined;

- in order to obtain more accurate results of the exterior orientation of images, a photogrammetric network has to be constructed prior to the execution of the aerial photography mission. In the case, when the images exterior orientation does not require high accuracy, it is sufficient to use the coordinates of each image projection center determined by GPS.

- an aerial photography should be realized by a camera with a stable optical system (fixed focal length and focus is not changed), with a sensor size of at least $12 \mathrm{MP}$, a radiometric resolution of 24 bits;

- overlapping of images is recommended up to 70$80 \%$ for acquisition of better results of matching images. In case of larger overlapping (e.g., 90\%), an excessive number of photographic images is obtained;

- aerial mapping products are specified selecting the step which generates orthogonal photographs.

The cost considerations of the Unmanned Aerial Vehicle application for the purpose of photogrammetry employment at experimental object are presented.

\section{References}

1. Černiauskas, E; Bručas, D. 2014. Daugiasraigčių sraigtaspanių naudojimo stebejjimo užduotims atlikti tyrimas. Aviacijos technologijos [Aviation technologies], 2(1): 53-58.

2. Eisenbeiss, H. 2009. UAV photogrammetry: Dissertation, Federal Institute of Technology (ETH), Institute of Geodesy and Photogrammetry, Zurich, Switzerland, Mitteilungen. $235 \mathrm{p}$.

3. Haala, N.; Cramer, M.; Weimer, F.; Trittler, M. 2011. Performance Test on UAV-Based Photogrammetric Data Collection, International Archives of the Photogrammetry, Remote Sensing and Spatial Information Sciences 38-1/C22: 7-12. http://dx.doi.org/10.5194/isprsarchives-XXXVIII-1-C22-7-2011.

4. Konecny, G. 2003. Geoinformation: Remote Sensing, Photogrammetry and Geographic information system. Taylor and Francis. 248 p.

5. Kraus, K. 2007. Photogrammetry: Geometry from Images and Laser Scans. Berlin: Walter de Gruyter. 459 p.

6. Linder, W. 2009. Digital Photogrammetry. A practical Course. Springer-Verlag, Berlin, Heidelberg. 33- 73, 121-131 p.

7. Manual of Photogrammetry (Edited by J. Chris McGlone). 2004. American Society for Photogrammetry and Remote Sensing, Maryland, USA. 959-963 p.

8. Neitzel, F.; Klonowski, J. 2011. Mobile Mapping with Low-Cost UAV System, International Archives of the Photogrammetry, Remote Sensing and Spatial Information Sciences 38-1/C22: 1-6. 
9. Rock, G.; Ries, J. B.; Udelhoven, T. 2011. Sensitivity Analysis of UAV-Photogrammetry for Creating Digital Elevation Models (DEM), International Archives of the Photogrammetry, Remote Sensing and Spatial Information Sciences 38-1/C22: 1-5.

10. Rudinskas, D. 2011. Bepiločiu orlaiviu skrydžio parametrụ matavimu duomenu perdavimo saugos metodikos sukūrimas: Daktaro disertacija. Vilniaus Gedimino technikos universitetas. Vilnius: Technika. 85 p.

11. Ruzgienè, B. 2008. Fotogrametrija. Vilnius: Technika. 93-132 p.

12. Ruzgienė, B; Aksamitauskas, V. Č.; Daugèla, I.; Prokopimas, Š.; Puodžiukas, V.; Rekus, D. 2015. UAV photogrammetry for road surface modelling. The Baltic journal of road and bridge engineering. Vilnius: Technika. Vol. 10, no. 2, p. 151-158.

13. Ruzgienė, B.; Berteška, T.; Gečytė, S.; Jakubauskienè, E.; Aksamitauskas, V, Č. 2015. The surface modelling based on UAV Photogrammetry and qualitative estimation. Measurement. Oxford: Elsevier Ltd. Vol. 73, p. 619-627.

14. Ruzgienė, B.; Gečytė, S.; Jakubauskienè, E. 2014. Užstatytų teritorijų kartografavimas, naudojant fotogrametrinius duomenis, gautus fotografuojant iš bepiločio skraidymo aparato. Inžinerinès ir edukacinés technologijos [Engineering and educational technologies]. Kauno technikos kolegija. Nr.1, p. 69-77.

15. Trimble, UX5. Available from Internet: http://uas.trimble.com/ux5 (9 September 2017).

16. Sauerbier, M.; Siegrist, E.; Eisenbeiss, H.; Demir, N. 2011. The Practical Application of UAV-Based Photogrammetry Under Economic Aspects. Remote Sensing and Spatial Information Sciences, Volume XXXVIII-1/C22, Zurich, Switzerland. 45-50 p.

17. UAV Systems-Unmanned Aerial Photography. AUVSI. http://www.uavsystems.com.au/ (2 September 2017).

18. Watts, A. C.; Ambrosla, V. G.; Hinkey E. A. 2012. Unmanned Aircraft Systems in Remote Sensing and Scientific. Research: Classification and Considerations of Use. Remote Sensing 4(6). 1671-1692 p. 